\title{
Application of a Cross-linked Polyacrylic Acid- Polyethylene Oxide (PAA-PEO) Copolymer as a Binder for Si@C@PDA Composite Anode Materials in Li-ion Batteries
}

\author{
Shibin Liu*, Xiangcai Meng, Jing Wang, Jianwei Xu, Hongbo Li \\ School of Materials Science and Engineering, Jiamusi University, Jiamusi 154007, China \\ *E-mail: christainvieri@126.com
}

Received: 9 September 2021 / Accepted: 17 November 2021 / Published: 5 January 2022

\begin{abstract}
In this paper, a PAA-PEO cross-linking binder was prepared by the copolymerization method and used in Si@C@PDA composite anode materials for Li-ion batteries. The phenolic hydroxyl in PAA-PEO and the hydroxyl in the self-polymerized PDA on the surface of Si@C can form a three-dimensional crosslinking binding system with strong hydrogen bonds. Compared with the traditional binder, PAA-PEO has higher adhesion and conductivity. The structure of Si@C@PDA-PAA-PEO was successfully determined by IR and XPS. The electrochemical results show that PAA-PEO can significantly improve the cycle stability of the Si@C@PDA composite negative electrode material, and can maintain a 600 $\mathrm{mAgh}^{-1}$ stable cycle 200 times under a $1000 \mathrm{mAg}^{-1}$ current density, and the first coulombic efficiency is $89.4 \%$.
\end{abstract}

Keywords: Li-ion battery,Crosslinking binder, dopamine,electrochemical properties.

\section{$\underline{\text { FULL TEXT }}$}

(C) 2022 The Authors. Published by ESG (www.electrochemsci.org). This article is an open access article distributed under the terms and conditions of the Creative Commons Attribution license (http://creativecommons.org/licenses/by/4.0/). 